\title{
Ocular toxicity of desferrioxamine: light microscopic histochemical and ultrastructural findings
}

\author{
A H S RAHI,' J L HUNGERFORD, ${ }^{2}$ AND A I AHMED \\ From the 'Institute of Ophthalmology, ${ }^{2}$ Moorfields Eye Hospital, and ${ }^{2}$ University College Hospital, London
}

SUMmARY This study documents for the first time light and electron microscopical changes in the retinal pigment epithelium (RPE) following treatment with high dose desferrioxamine for systemic iron overload. The changes include loss of microvilli from the apical surface, patchy depigmentation, vacuolation of the cytoplasm, swelling and calcification of mitochondria, and disorganisation of the plasma membrane. In addition, Bruch's membrane overlying degenerate RPE cells appeared abnormally thickened owing to the accumulation of large amounts of mature elastic fibres, pre-elastic oxytalan, and long spacing collagen. The specificity of these changes and the mechanism of toxicity are discussed.

Desferrioxamine (diethylenetriamine penta-acetic acid), an iron chelating agent, is extensively used for the treatment of systemic iron overload, ocular siderosis, and corneal rust staining. It was first isolated in $1960^{\prime}$ from sideramine, an iron-containing metabolite of actinomyces. Ocular toxicity of desferrioxamine came to light only recently when four patients with $\beta$-thalassaemia major were treated with a high intravenous dose to counter the effects of transfusion-induced iron overload. ${ }^{2}$ Two patients developed night blindness and field defects which were improved on withdrawal of the drug. Recently one of the two affected patients died from heart

Correspondence to Mr J L Hungerford, FRCS, Moorfields Eye Hospital, City Road, London EC1V 2PD.

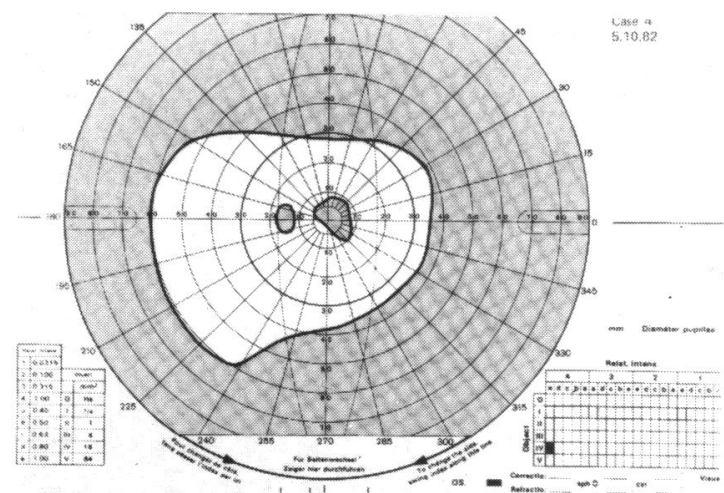

failure, and we were able to obtain an eye to study the structural lesions of ocular toxicity. We report here the relevant histochemical, light microscopic, scanning, and transmission electron microscopic findings.

\section{Material and methods}

The deceased was a 24-year-old male who had received regular blood transfusion from the age of 6 months for the treatment of $\beta$-thalassaemia major. He underwent splenectomy at the age of 16 years. To prevent iron overload and subsequent damage to the liver and other organs he received intramuscular desferrioxamine $500 \mathrm{mg}$ daily from age 8 years. From age 19 he received his desferrioxamine by overnight subcutaneous infusion.

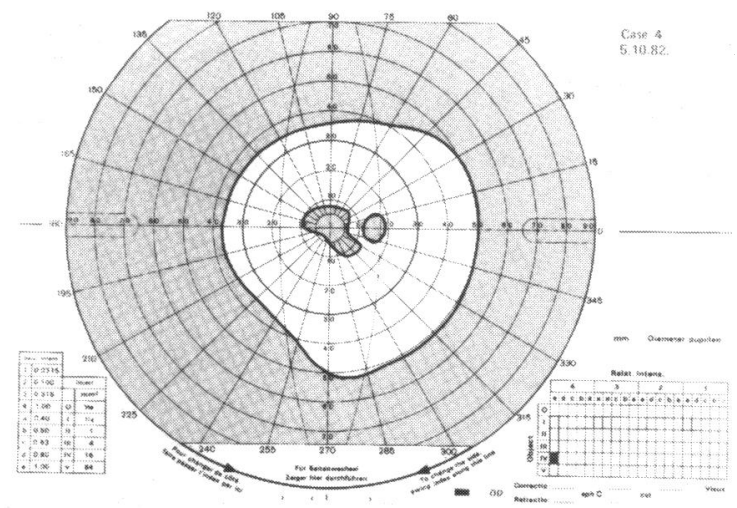

Fig. 1 Visual fields during high-dose desferrioxamine therapy. 

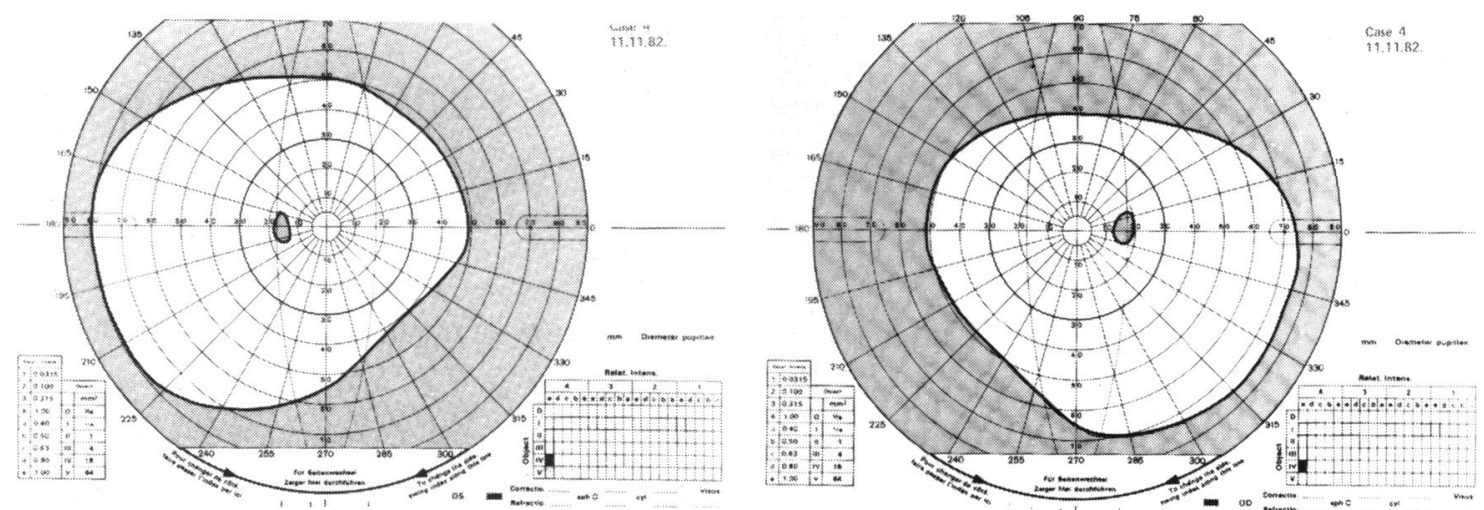

Fig. 2 Visual fields after withdrawal of high-dose desferrioxamine therapy.

In 1982 he was admitted as an emergency and was treated for congestive cardiac failure at University College Hospital, London. His serum ferritin was very high $(11000 \mu \mathrm{g} / \mathrm{l})$ and intravenous desferrioxamine was started, $165 \mathrm{mg} / \mathrm{kg}$ per $24 \mathrm{~h}$ for two days, then $220 \mathrm{mg} / \mathrm{kg}$ per $24 \mathrm{~h}$ for six days. Eight days after the start of intravenous therapy he complained of poor vision in dim light. The treatment was stopped. Detailed ophthalmological examination showed bilateral reduced visual acuity $(6 / 36)$ and impaired colour vision. Visual field examination revealed a small central scotoma in each eye and generalised constriction of the peripheral field (Fig. 1). Within what field remained, scotopic static perimetry showed a reduction in dark adaptation greatest in the central and equatorial zones. There were no lens opacities or obvious pigmentary disturbance in the retina, but the retinal vessels were thin and tortuous. The electro-oculogram (EOG) was severely reduced and the Ganzfeld electroretinogram (ERG) was
Fig. 3 Paraffin section of the eye showing iron-containing stromal cells in the choroid. Note that occasional retinal pigment epithelial cells are enlarged and appear to project towards the photoreceptors, which appear normal. (Perls's stain, $\times 250)$.

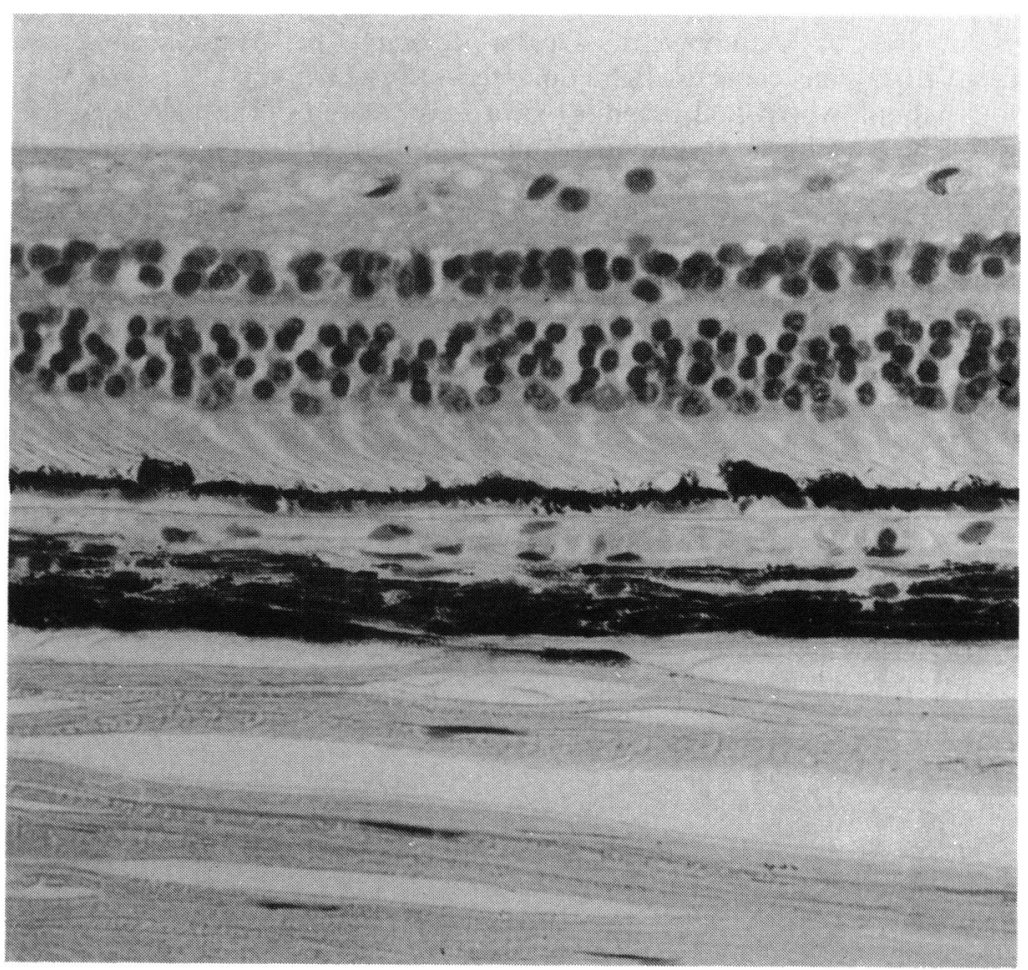




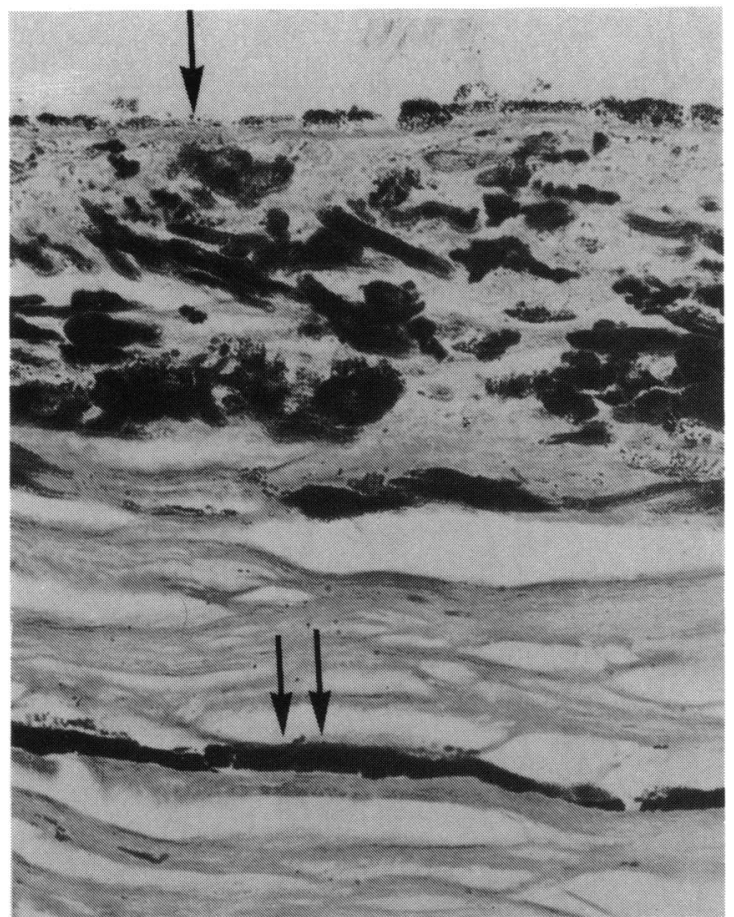

Fig. 4 Degeneration and patchy depigmentation of retinal pigment epithelium (single arrow); the choroid contains many pigmented stromal cells. Pigment-containing cells are also present in the sclera (double arrows). (Perls's stain, $\times 590)$.

subnormal. The pattern visual evoked response (VER) showed a reduction in sensitivity, and there was a poor response on the pattern ERG. After the withdrawal of high-dose therapy there was a rapid subjective improvement in vision. Two months later colour vision had returned to normal in each eye. The central scotomas had disappeared and the peripheral field constriction had recovered to within normal limits (Fig. 2). The visual acuity was 6/9 (right) 6/12 (left). The pattern ERG, however, was still subnormal, and there was some loss of scotopic sensitivity.

In August 1983 the patient died of severe congestive cardiac failure. The body was refrigerated and the eye was removed five hours after death. The globe was placed in $3 \%$ gluteraldehyde in cacodylate buffer ( $\mathrm{pH} 7.4)$ after a corneal disc had been trephined out to allow rapid penetration of fixative. Forty-eight hours later small pieces of the retina along with the attached choroid and the sclera were excised from various regions of the globe and postfixed in $1 \%$ isotonic osmium tetroxide. The retina and the choroid were dehydrated in ascending grades of ethanol and finally embedded in araldite. Ultra- thin sections $(50-80 \mathrm{~nm})$ were stained with uranyl acetate and lead citrate, and selected areas were studied with the JEOL-JEM 100C transmission electron microscope. For scanning electron microscopy tissue was dehydrated, critical point dried, sputter coated, and examined in a Hitachi S-520 scanning electron microscope. The remaining portion of the globe was processed for routine paraffin embedding. Sections were stained with haematoxylin and eosin. Perls's stain (Prussian blue reaction) was used to demonstrate deposits of iron in ocular tissues.

\section{Results}

Microscopical examination of the whole eye sections (Figs. 3-6) showed deposits of iron in the nonpigmented ciliary epithelium, the ciliary muscle, stromal cells of the choroid, the sclera, and the peripheral retina, which also showed cystoid degeneration. Only occasionally were iron deposits seen in the photoreceptor layer or in the pigment epithelium. The latter showed, however, patchy depigmentation in the equatorial as well as the posterior fundus. In places the retinal pigment epithelium (RPE) cells appeared enlarged and projected into the subretinal space, which sometimes contained detached and rounded up RPE cells containing typical melanin granules. There was no evidence of melanin deposits, however, in the sensory retina around retinal blood vessels.

Scanning electron microscopy (SEM) showed well distributed microvilli on the apical surface of the normal RPE cells. In the equatorial and the posterior regions, where by light microscopy there was evidence of patchy degeneration, with SEM the degenerating pigment epithelial cells showed retraction of villi, or even their total loss, and some of the cells appeared to have large holes (Figs. 7, 8).

Transmission electron microscopy (Figs. 9, 10, 11). The most important changes were observed in the retinal pigment epithelial cells, which showed a variety of structural alterations. Some of the cells had ragged borders, and the basal infolding of plasma membrane had disappeared. The cytoplasm had several alveoli, mitochondria were swollen, and some showed evidence of calcification. The retraction of cytoplasmic extensions produced apparent gaps between cells. Bruch's membrane under the degenerate or depigmented epithelial cells was abnormally thickened and showed the presence of mature elastic tissue, pre-elastic oxytalan fibres, and long-spacing bundles. However, the photoreceptors were normal and did not show any obvious abnormality in either the mitochondria or other organelles. 
Fig. 5 The peripheral retina shows cystoid degeneration and contains scattered pigment granules. (Perls's stain, $\times 250$ ).

Fig. 6 The non-pigmented epithelium of the ciliary body is filled with iron pigment (double arrows). Similar deposits are also present in the ciliary muscle (arrow). (Perls's stain, $\times 250$ ).
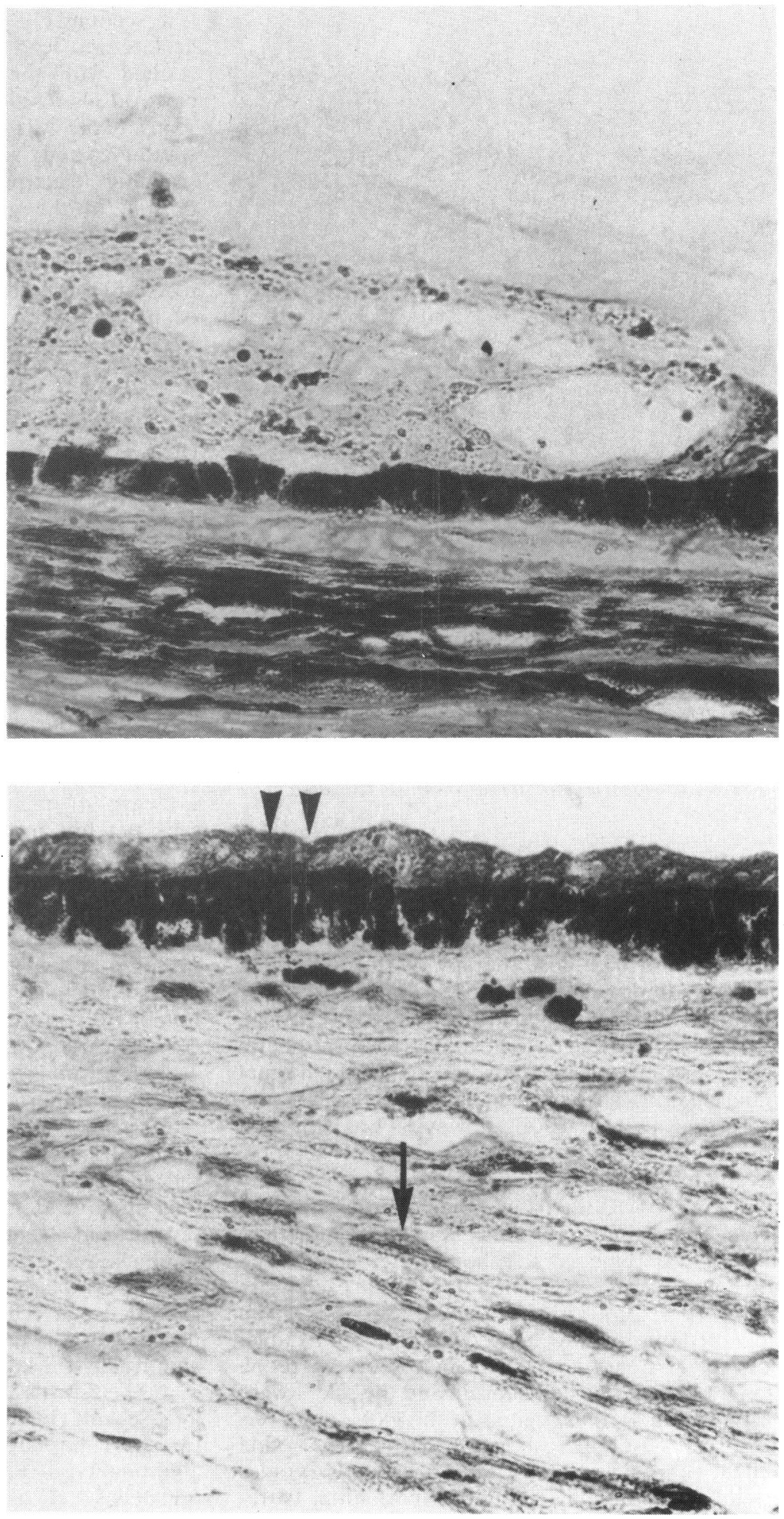


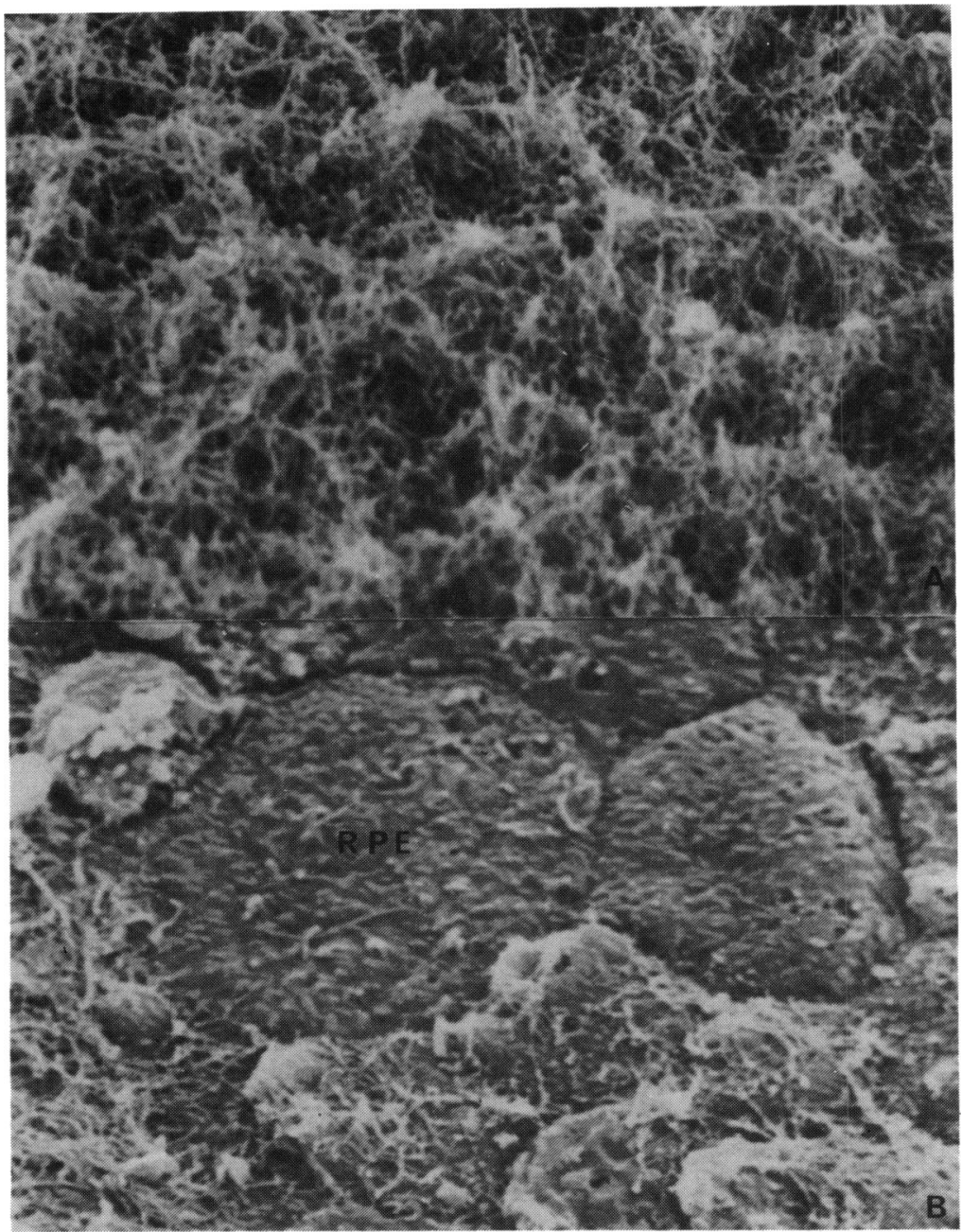

Fig. 7 Scanning electron micrograph of retinal pigment epithelium. (A) Unaffected cells are covered by numerous microvilli. (B) Several enlarged cells (RPE) in the affected equatorial zone of the retina show apparent loss of microvilli. $(\times 6100)$.

\section{Discussion}

A variety of drugs is known to produce retinal toxicity, ${ }^{3}$ the most important being chloroquine and thioridazine. This is the first time, however, that an eye showing retinotoxicity following administration of a high dose of systemic desferrioxamine has been examined by light and electron microscopy. Clinically detectable lens opacities have been reported before ${ }^{4}$ but visual failure due to a presumed toxic effect of this drug has only recently been observed. ${ }^{2}$ There are three possible explanations for the changes discovered in the RPE and Bruch's membrane: a simple post-mortem artefact, the effect of ocular siderosis in association with systemic iron overload, or a true toxic effect of the drug desferrioxamine.

We believe that the structural abnormalities were real rather than post-mortem because the changes in the RPE were patchy, and degenerate cells were always found in the company of apparently normal cells. Furthermore, it has been shown in another scanning electron microscopic study ${ }^{5}$ that eyes processed several hours after death did not show any loss of microvilli on the apical side of the RPE. It could be argued that the artefactual detachment of the retina which occurred during processing may have caused the loss of microvilli seen in the present case. Against this is the observation that similar changes have not been detected in experimental retinal detachment, ${ }^{6}$ although Sakuragawa and Kuwabara have reported that, if the sensory retina is forcibly pulled out, occasional RPE cells may show total loss of microvilli. Calcification of mitochondria and thickening of Bruch's membrane are definite signs of degeneration and could never be regarded as artefactual. The 
Fig. 8 Scanning electron micrograph showing patchy degeneration of retinal pigment epithelium (RPE) as evidenced by retraction of and in some cases apparent loss of surface microvilli in some cells (single arrows). One cell in the lower left corner appears to have burst open (double arrows). $(\times 6100)$.

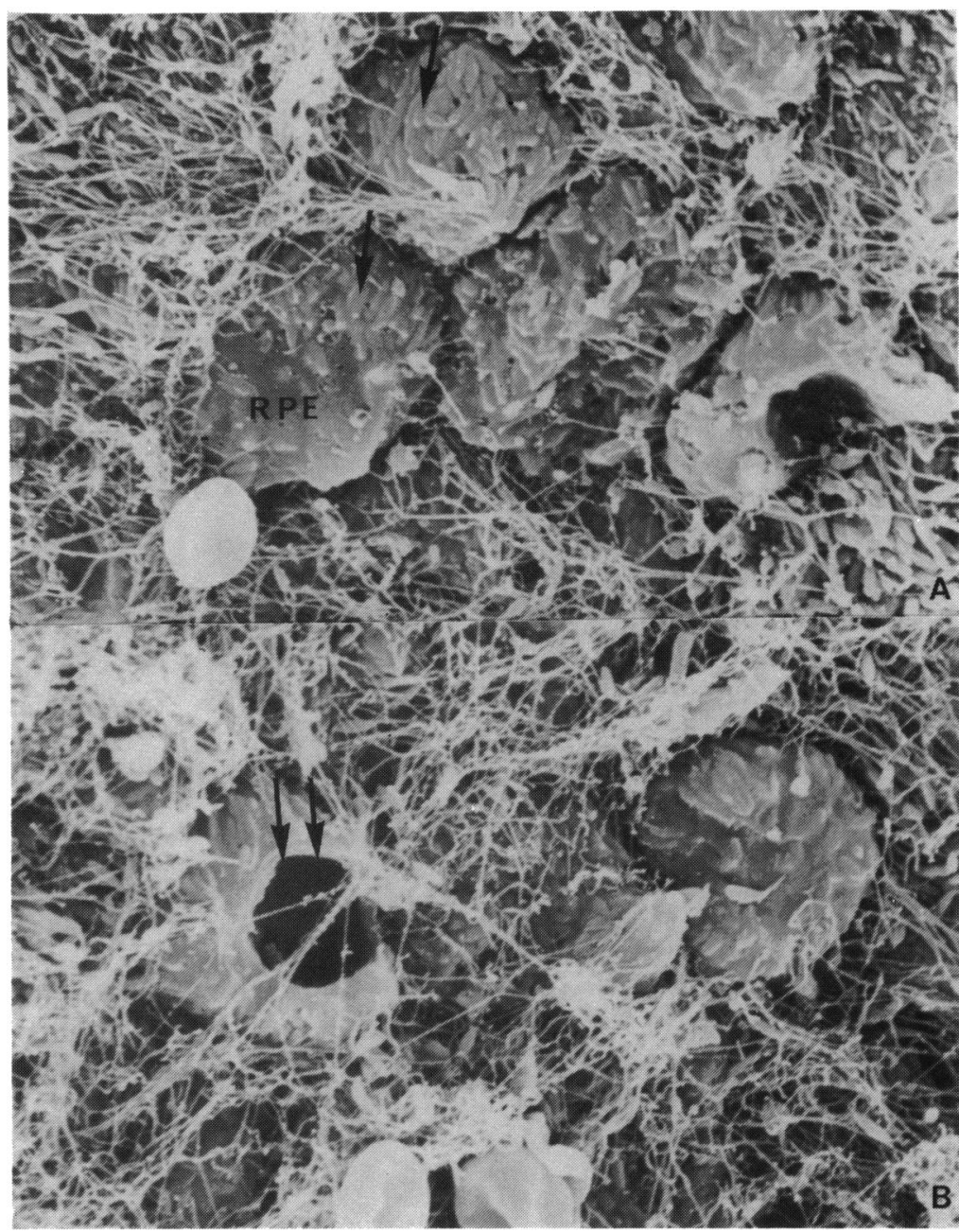

seen in the present case may represent a common endpoint for a variety of pathological processes affecting the RPE.

Whether or not the changes observed in the RPE cells and in Bruch's membrane were in part due to ocular siderosis is difficult to determine, but we believe that their main cause was a toxic effect of the drug desferrioxamine. We take this view firstly because there was clinical recovery of the RPE after treatment with the drug was stopped, whereas withdrawal of desferrioxamine would have been most unlikely to be followed by an improvement had ocular siderosis been the main cause of visual failure. Secondly, systemic iron overload in experimental animals (unpublished observation) fails to produce electrophysiological changes in the retina, suggesting that such overload does not lead to ocular siderosis. Thirdly, in support of the latter observation there was 


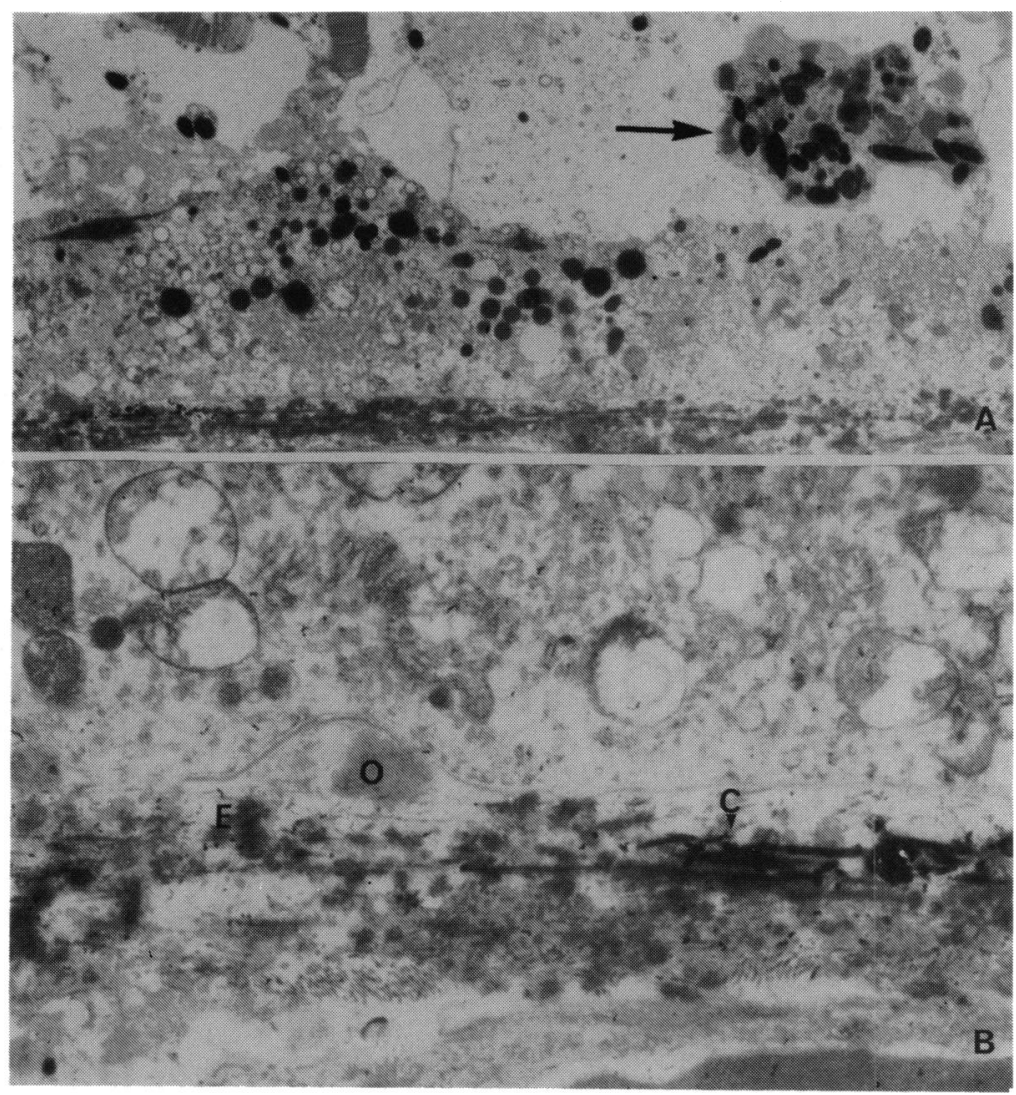

Fig. 9 Transmission electron microscopic appearance of the pigment epithelial cells in the equatorial region of retina. (A) Degenerating RPE; a detached cell (arrow) which contains typical spindle shaped granules is present in the subretinal space. $(\times 2820)$. (B) Higher magnification to show swelling of the mitochondria and gross thickening of Bruch's membrane due to accumulation of mature elastic fibres $(\mathrm{E})$; long-standing collagen and pre-elastic oxytalan $(\mathrm{O})$; denatured collagen $(\mathrm{C}) .(\times 11570)$.

no evidence of iron deposition in the degenerate RPE cells of the present case. Clinically, therefore, ocular siderosis differs from desferrioxamine toxicity in that, while in the former it is administration of the drug which brings about improvement in vision, in the latter it is its withdrawal.

The mechanism of pigment epithelial damage in this case is not clear. Since desferrioxamine chelates not only iron but also copper, zinc, cobalt, and nickel, it is possible that the visual changes were due to the removal of trace elements from the retina. It is known that urinary excretion of copper and zinc is increased during desferrioxamine infusion. Since copper metabolism appears to be defective in some cases of retinitis pigmentosa, ${ }^{11}{ }^{12}$ it is possible that the retinal changes in this case were also due to altered levels of copper leading to inadequacy of copperdependent intracellular oxidative processes.

Low levels of copper in Menkes's disease are associated with an abnormal ERG and VER, defective melanin formation in the RPE, and absence of elastic tissue in Bruch's membrane. Since Bruch's membrane in the present case showed the presence of both mature elastic tissue and pre-elastic oxytalan fibres, these changes cannot be explained simply on the basis of iatrogenic altered copper metabolism. ${ }^{13}$ Whatever may be the mechanism of retinotoxicity, it would seem that, in patients with iron-overload, prolonged use of desferrioxamine in low doses is without serious ocular consequences.

Possibly the improvement in vision in the present case which followed the withdrawal of high-dose desferrioxamine was associated with limited reversal of the pathological changes. From the clinical and histopathological findings the retinotoxicity produced by a high dose of systemic desferrioxamine would seem to be reversible if diagnosed early. It is therefore important to follow up patients on highdose therapy ophthalmologically and to detect retinopathy in its earliest stages. The subtle changes may be thought to be unrelated to medication, especially in patients not examined prior to therapy. Although the ERG and EOG are not always abnormal in other forms of retinotoxicity, ${ }^{14}$ they may be diagnostic in the toxicity attributable to high-dose intravenous desferrioxamine. 
Fig. 10 A retinal pigment epithelium cell in the central retina showing swelling and calcification of mitochondria (arrow). Note that the cell is almost non-pigmented $(\times 14400)$.

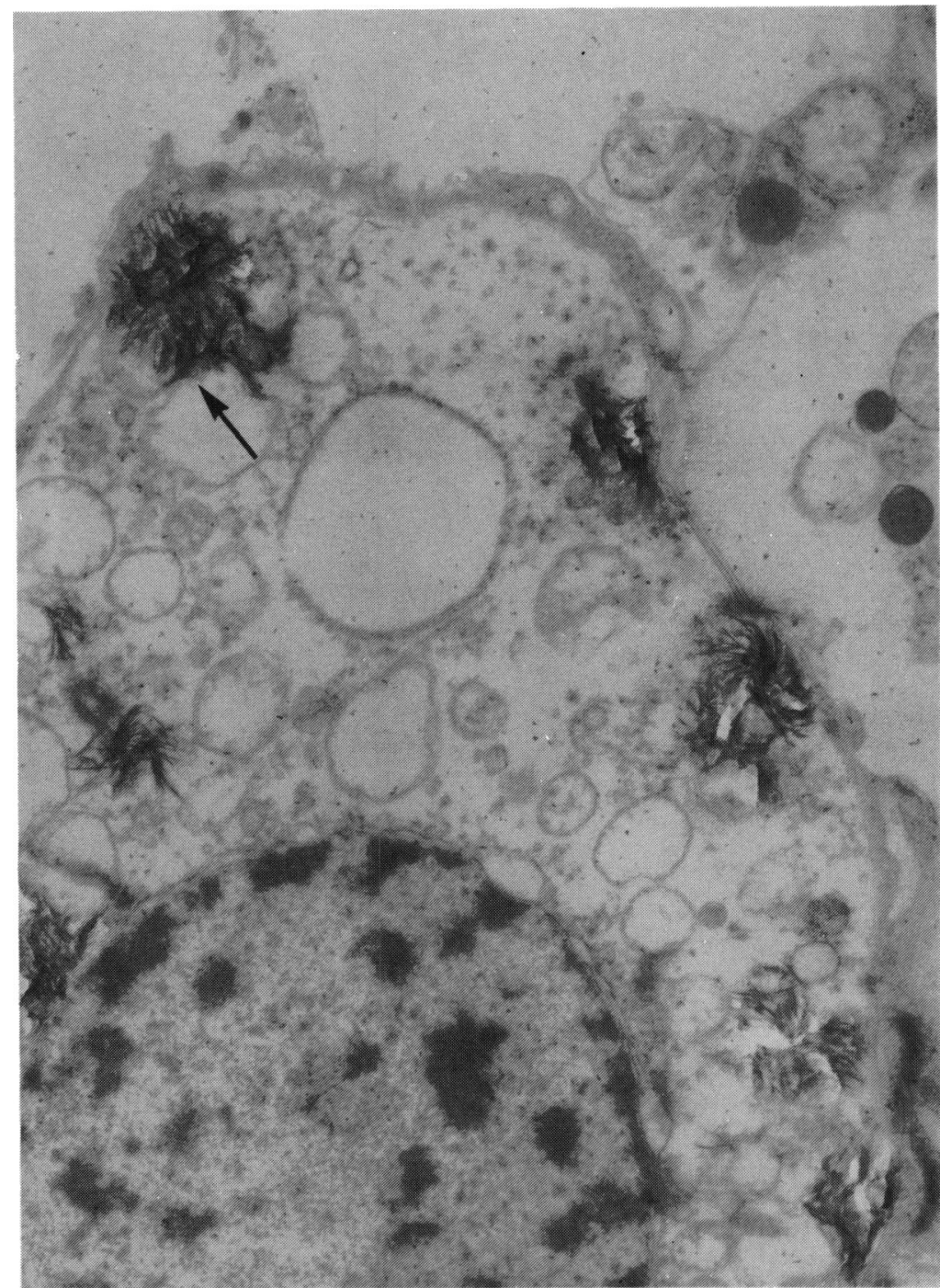

Figs. 1 and 2 are reprinted with kind permission of the Editor of the Lancet.

\section{References}

1 Bickel H, Gaeumann E, Keller-Schierlein W, et al. On ironcontaining growth factors, sideramines, and their antagonists the iron-containing antibiotics, sideromycins. Experientia 1960; 16: 129-33.

2 Davies S, Marcus RE, Hungerford JL, et al.Ocular toxicity of high-dose intravenous desferrioxamine. Lancet 1983; ii: 181-4.

3 Grant WM. Toxicology of the eye. 2 nd ed. Springfield: Thomas, 1974: 34-54.

4 Bloomfield SE, Markeson AL, Miller DR, Petterson CM. Lens opacities in thalassemia J Pediatr Ophthalmol Strabismus 1978; 15: $154-4$.

5 Goldbaum, MH, Madden K. A new perspective of Bruch's membrane and retinal pigment epithelium. Br J Ophthalmo 1982; 24: 906-26.

6 Anderson DH, Stern WH, Fisher SK, Erickson PA, Bongula GA. Retinal detachment in the cat: pigment epithelialphotoreceptor interface. Invest Ophthalmol Vis Sci 1983; 24: 906-26.

7 Sakuragawa M, Kuwabara T. The pigment epithelium of monkey. Arch Ophthalmol 1976; 94: 285-92.

8 Rosenthal AR, Kolb H, Bergsma D, Huxsoll D, Hopkins JL. Chloroquine retinopathy in rhesus monkey. Invest Ophthalmol Vis Sci 1978; 17: 1158-75.

9 Wise JB. Treatment of experimental siderosis bulbi, vitreous hemorrhage and corneal blood staining with desferrioxamine. Arch Ophthalmol 1966; 75: 698-707.

10 Ashburn FS, Pilkerton AR, Rao NA, Marak GE. The effect of iodate and iodoacetate on the retinal adhesion. Invest Ophthalmol Vis Sci 1980; 19: 1427-32. 


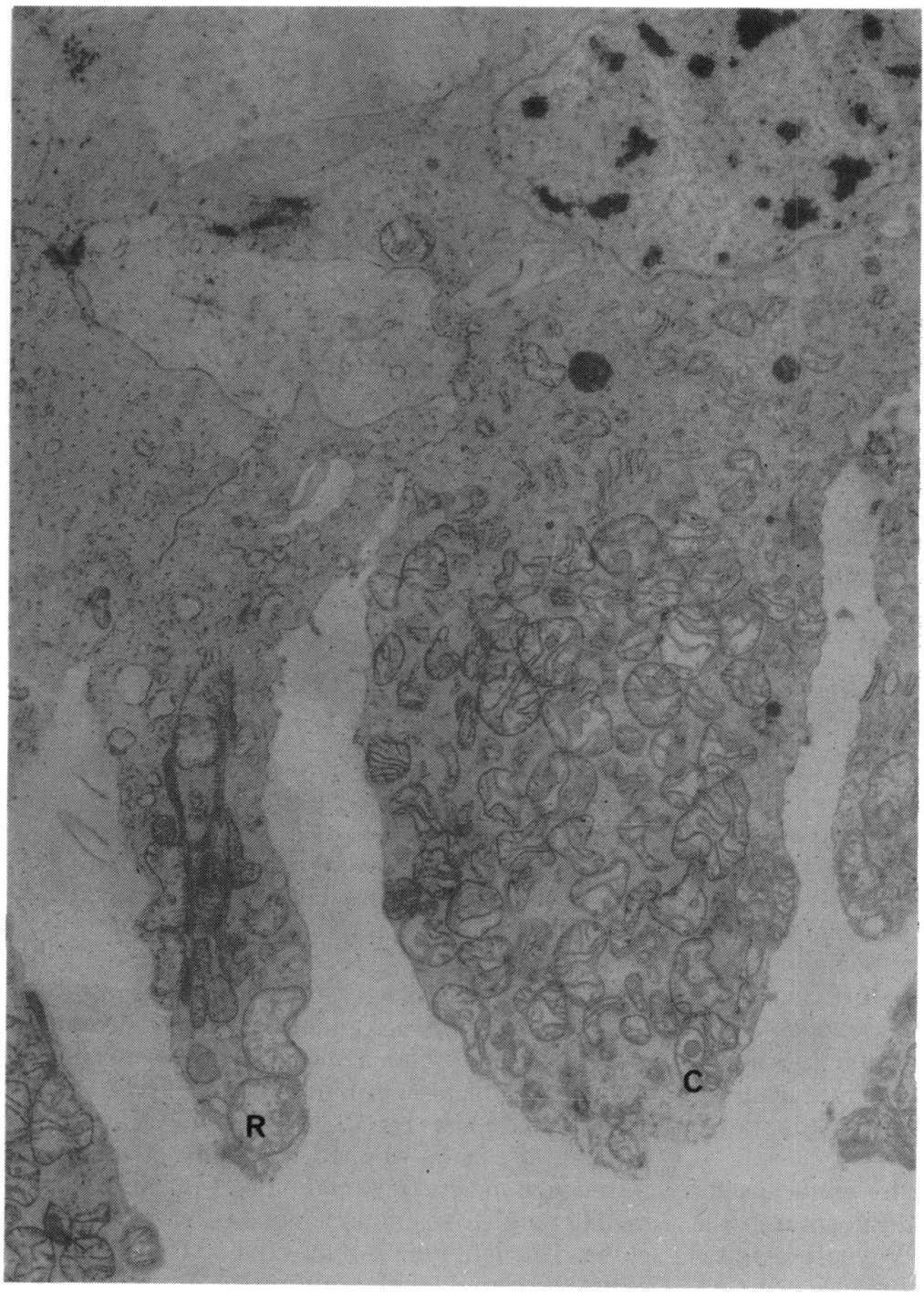

Fig. 11 Transmission electron micrograph showing rod $(\mathrm{R})$ and cone (C) inner segment. Note that mitochondria are well preserved, further supporting the view that changes in the retina were specific, not a post-mortem artefact. The outer segment was artefactually detached during processing. $(\times 5670)$.

11 Rao SS, Satapathy M, Sitaramayya A. Copper metabolism in retinitis pigmentosa patients. Br J Ophthalmol 1981; 65: 12730.

12 Silverstone B, Berson D, Kuperman O. Copper metabolism changes in pigmentary retinopathies and high myopes. Metab Pediatr Syst Ophthalmol 1981; 5: 45-8.
13 Alexander RA, Garner A. Elastic and precursor fibres in the normal human eye. Exp Eye Res 1983; 36: 305-15.

14 Gouras P, Gunkel RD. The EOG in chloroquine and other retinopathies. Arch Ophthalmol 1963; 70: 629-39.

Accepted for publication 10 October 1985. 